\title{
First quantitative survey delineates the distribution of chimpanzees in the Eastern Central African Republic
}

\author{
Thierry Aebischer ${ }^{\mathrm{a}, \mathrm{b}}$, Guy Siguindo ${ }^{\mathrm{b}}$, Estelle Rochat ${ }^{\mathrm{c}}$, Mimi Arandjelovic ${ }^{\mathrm{d}}$, Amy Heilman ${ }^{\mathrm{d}}$, \\ Raffael Hickisch ${ }^{\mathrm{e}}$, Linda Vigilant ${ }^{\mathrm{d}}$, Stéphane Joost ${ }^{\mathrm{c}}$, Daniel Wegmann ${ }^{\mathrm{a}, *}$ \\ a Department of Biology, University of Fribourg, Chemin du Musée 10, CH-1700 Fribourg, Switzerland \\ b Chinko Project, 544 Rue de la Victoire, Bangui BP 3193, Central African Republic \\ ${ }^{\mathrm{c}}$ Laboratory of Geographic Information Systems (LASIG), School of Architecture, Civil and Environmental Engineering (ENAC), École Polytechnique Fédérale de Lausanne \\ (EPFL), CH-1015 Lausanne, Switzerland \\ d Max Planck Institute for Evolutionary Anthropology, Department of Primatology, Deutscher Platz 6, DE-04103 Leipzig, Germany \\ e WildCRU University of Oxford, Department of Zoology, Tubney, GB-ENG, UK
}

\section{A R T I C L E I N F O}

\section{Keywords:}

Pan troglodytes schweinfurthii

Camera trap

Nest count

Species distribution

Conservation plan

Chinko Nature Reserve

\begin{abstract}
A B S T R A C T
Vast, pristine ecosystems and their biodiversity are vanishing globally at frightening speed, but many large tracts of wilderness have not yet been systematically inventoried and important natural populations of threatened species remain poorly characterized. The forest-savanna ecotone of the Eastern Central African Republic (CAR) is one such poorly studied area. Using camera traps, transect walks and collected fecal samples, we provide the first quantitative survey of chimpanzees (Pan troglodytes) in this region previously classified as a highly important chimpanzee conservation unit. In contrast to species distribution models and expert predictions, we did not find any evidence of chimpanzees in the large and remote forest blocks west of the Chinko River despite considerable search effort. Our study thus highlights the limitations of relying solely on remote sensing data to predict the presence or absence of endangered species and illustrates the necessity of extensive field surveys to accurately assess occurrence and density in remote areas. However, we did discover a sizeable and reproducing population of chimpanzees east of the Chinko River. Based on a density of 0.81 chimpanzees $/ \mathrm{km}^{2}$ in closed canopy forest that we inferred from nest count data, we estimate 910 weaned chimpanzees to inhabit the Chinko Nature Reserve (CNR) and further predict additional 2700 individuals in adjacent, unmanaged hunting zones and reserves. According to microsatellite data, these chimpanzees genetically cluster with $P$. $t$. schweinfurthii populations in East Africa. Conservation action and appropriate management plans are urgently needed to protect this important population and to prevent heavily-armed nomadic pastoralists from the Sahel, illegal miners, as well as elephant and meat poachers, from irretrievably destroying the natural vegetation and local biodiversity of the area.
\end{abstract}

\section{Introduction}

We are currently facing a dramatic loss of biodiversity as well as naturally functioning ecosystems, and the conservation and preservation of these require substantial international effort (UNEP-WCMC and IUCN, 2016; WWF, 2016). In order to assess current levels of threat, we prioritize focal areas and propose appropriate and cost-effective conservation actions, requiring detailed and localized knowledge on the status of biodiversity and endangered wildlife populations (Oates, 2006; Schipper et al., 2008; Stuart et al., 2004; Tear et al., 1993). Interestingly, the biodiversity of some of the largest remaining wilderness areas such as vast parts of the Amazonian basin or central Africa, have not yet been systematically assessed and often not even inventoried (Hicks et al., 2014; Schipper et al., 2008). As a result, entire ecosystem communities, but also major populations of threatened species, are widely neglected in current conservation action plans (Darwall et al., 2011; Riggio et al., 2012).

A particularly understudied wilderness area is the Eastern Central African Republic (CAR), a heterogeneous ecotone of pristine moist forests and open savanna woodlands (Blom et al., 2004; East, 1999; Roulet et al., 2007). Our recent surveys in this region revealed an astonishingly large diversity of species, including chimpanzees (Pan troglodytes). Much of the forest and savanna-woodland of the southeastern CAR was traditionally assumed to be occupied by chimpanzees (Fig. 1,

\footnotetext{
* Corresponding author at: University of Fribourg, Chemin du Musée 10, CH-1700 Fribourg, Switzerland.

E-mail address: daniel.wegmann@unifr.ch (D. Wegmann).
} 


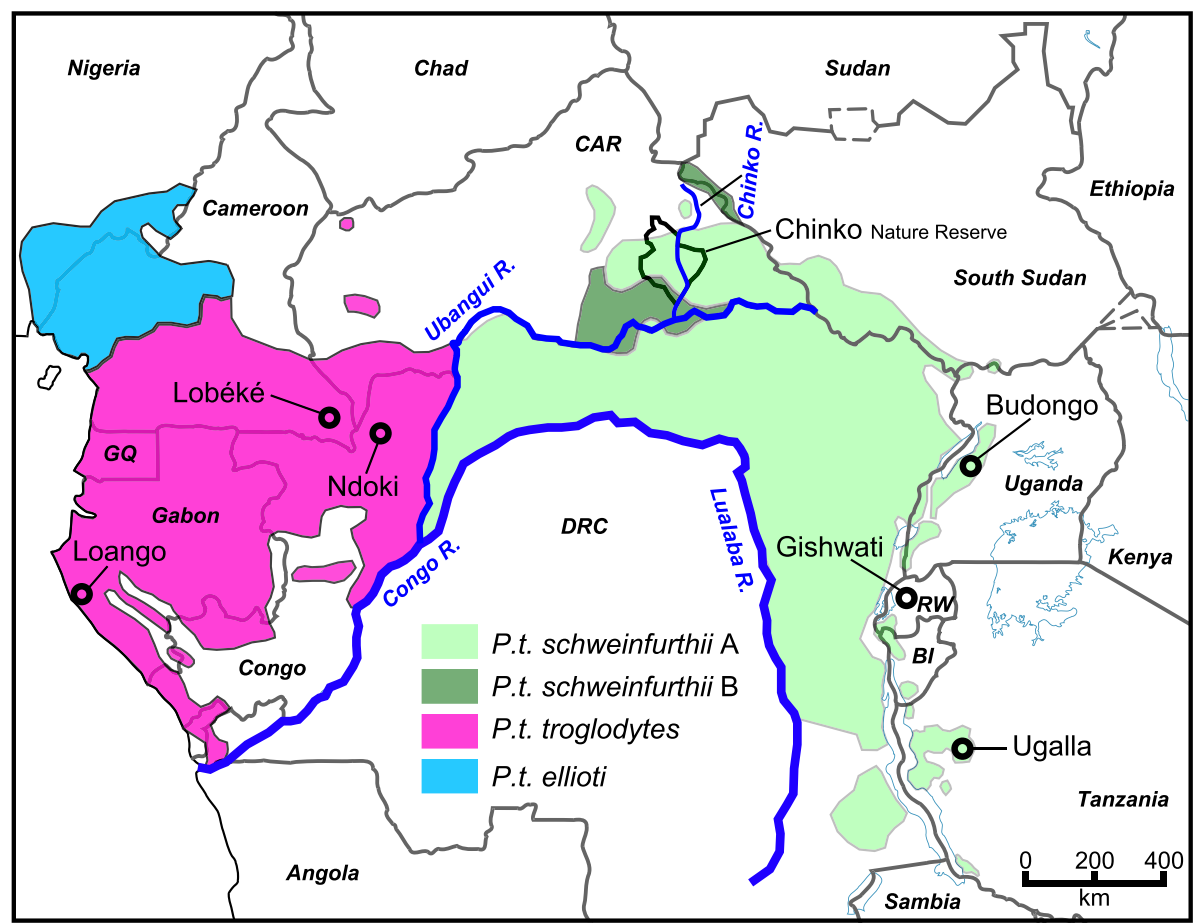

Fig. 1. Shown is the location of the Chinko Nature Reserve (CNR) in the Eastern Central African Republic (CAR) along with the assumed distribution of the Eastern (green), Central (magenta) and Nigerian-Cameroon (blue) chimpanzees. For Eastern Chimpanzee, two distributions are indicated: A) based on (Butynski, 2001) with updates from IUCN (IUCN SSC A.P.E.S. database, Drexel University and Jane Goodall Institute, 2016), B) additional areas based on revised map from (Plumptre et al., 2010). Dots indicate chimpanzee populations used to assign genotypes from the CNR. GQ = Equatorial Guinea, DRC = Democratic Republic Congo, $\mathrm{RW}=$ Rwanda, $\mathrm{BI}=$ Burundi. Map of Africa adapted from (Wikimedia, 16:45, 7 April 2011). (For interpretation of the references to color in this figure legend, the reader is referred to the web version of this article.)
(Butynski, 2001; Caldecott and Miles, 2005; Goodall, 1986; Hillman, 1982; Kormos et al., 2003; Oates et al., 2008; Plumptre et al., 2010; Tuttle, 1986), but to our knowledge, no systematic field survey was ever conducted in this region. In addition, historical reports of chimpanzees from this region are extremely rare and mostly vague (Henriot, 2014; Kormos et al., 2003), yet anecdotal evidence by safari hunters and operators suggested that chimpanzees had been observed east of the Vovodo River (Plumptre et al., 2010). In line with this, two chimpanzee nest sites and footprints were spotted during a two-week reconnaissance survey in the Zémongo Reserve (Roulet et al., 2007), but no evidence of chimpanzees was found during two elephant surveys west of the Chinko River including the Bangassou forest constituting the largest forest patch in the Eastern CAR (Fay, 1991; Williamson et al., 2004).

In contrast to these limited records, two recent ecological modeling approaches across all of Africa predicted the habitat of the Eastern CAR to be largely unsuitable for chimpanzees, except for isolated patches southwest of the Chinko river where occurrences were predicted to be more likely (Junker et al., 2012; Plumptre et al., 2010). Given the conflicting information, the Eastern Chimpanzee Status Survey and Conservation Action Plan 2010-2020 (Plumptre et al., 2010) predicted a chimpanzee conservation unit (CCU) east of the Vovodo river and ranked it as the 5th most important CCU for conservation given the expected ecological uniqueness of a chimpanzee population in the Eastern CAR, but identified the area southwest of the Chinko river as one of the five priority areas for further surveys. Interestingly, the area in between these rivers was largely considered void of chimpanzees. However, the report also acknowledged limitations of the modeling approaches used due to a clear lack of data, and emphasized an urgent need for surveys in that region to determine the current status of chimpanzees and to identify priority populations and major conservation threats.

Here we report the results of an extensive chimpanzee survey in the Eastern CAR that revealed the presence of a robust but threatened population of chimpanzees. Using the collected data we address four main questions about this population: 1 . What is the current spatial distribution of chimpanzees in the Eastern CAR? 2. What is the density and structure of the chimpanzee population in the region? 3 . What is the habitat preference of chimpanzees in this forest-savanna ecotone? 4. What is the relationship with other known chimpanzee populations outside the CAR? Answers to these questions will provide critical information about chimpanzees in the Eastern CAR and form the basis for the development of a chimpanzee conservation action plan for that region.

\section{Material and methods}

\subsection{Study area}

The headwaters of the rivers Kotto, Mbari, Chinko and Ouara in Eastern CAR belong to the last continuous savanna and rainforest ecosystems in Africa without permanent human settlements (Fig. 1). Remotely accessible from few main roads surrounding the area and the four major rivers crossing it from north to south, the region encompasses about $85000 \mathrm{~km}^{2}$ of virtually intact Medio-Sudanian and Sudano-Guinean savanna with patches of Congolian lowland rain forest along rivers, streams and gorges. Average annual precipitation varies from 1,000 ( \pm 90 ) to 1500 ( \pm 180 ) mm (Adler et al., 2003; Boulvert, 1986; Cmap and NOAA, 2012) on a gradient from northeast to southwest. There is one single rainy season from end of March until October peaking in August, followed by a dry season. Average monthly temperatures range between $22.5{ }^{\circ} \mathrm{C}( \pm 0.5)$ in December and $27.5^{\circ} \mathrm{C}$ $( \pm 1.0)$ in April. No forestry or agricultural exploitation takes place in the study area, but localized illegal mining, meat and ivory poaching as well as ever increasing temporal grazing by nomadic pastoralists from the Sahel are found throughout the region (Blom et al., 2004; Roulet et al., 2007; Tidjani, 2015). The entire Chinko River basin and adjacent regions in the Eastern CAR are officially classified as hunting zones or nature reserves and represent one of the largest formally protected wildlife areas in Africa. Currently only few hunting zones are actively managed and the Zémongo Faunal Reserve, as other reserves and national parks in the north, is currently not managed (Blom et al., 2004). This study took place in the Chinko Nature Reserve (CNR), an official conservation area created in 2014 and encompassing the former hunting zones Bas Chinko 48, Chinko 40, Mbari 39 and Vovodo Chinko 41. The reserve was created by the government of the CAR in close 


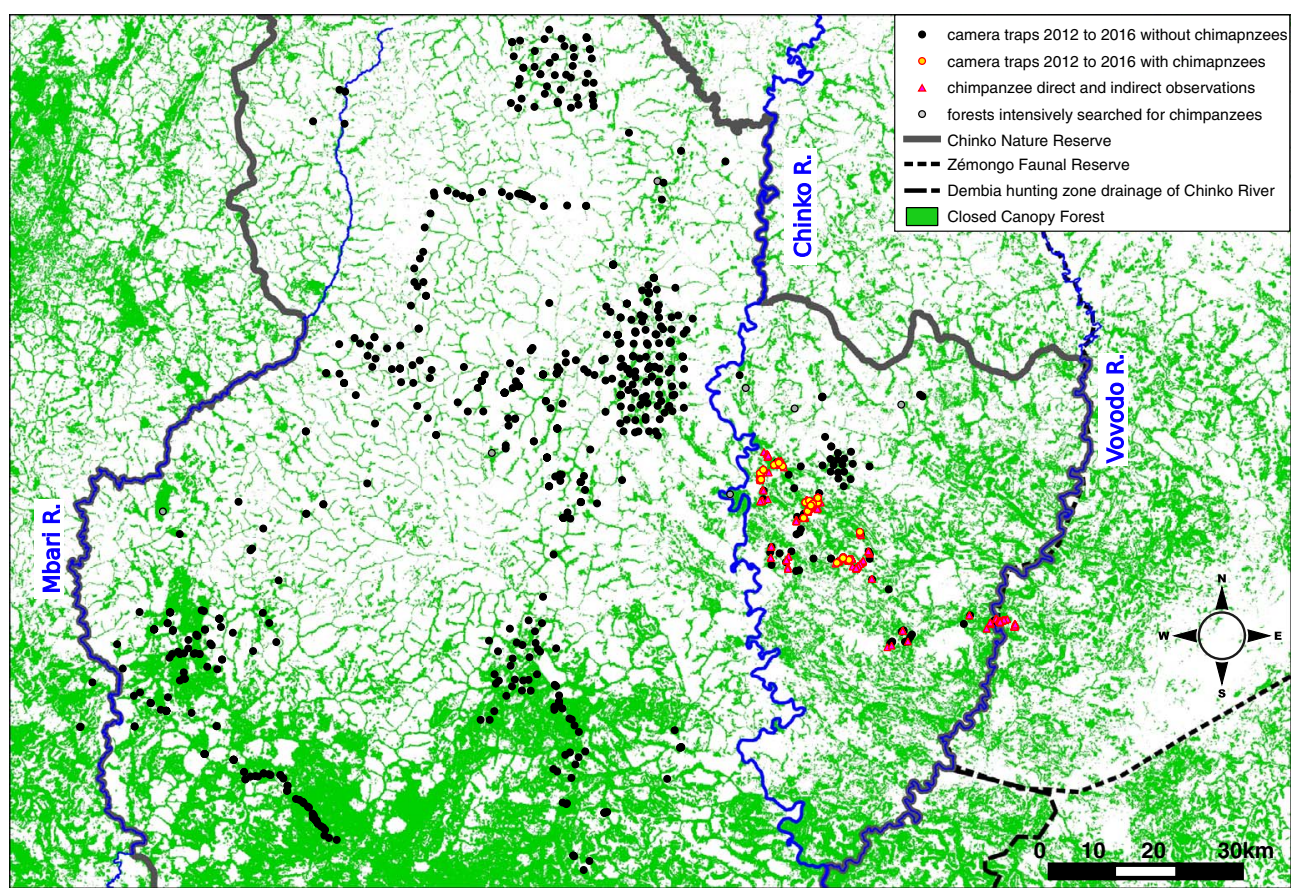

Fig. 2. Study area between the three major rivers, Mbari, Chinko and Vovodo within the assumed species range of chimpanzees (IUCN SSC A.P.E.S. database, Drexel University and Jane Goodall Institute, 2016; Kormos et al., 2003). Green surfaces indicate closed canopy forests (CCF). Dots indicate camera trap locations (2012-2016) with (yellow and red) and without (black) chimpanzee events. For better readability, we do not show the $1750 \mathrm{~km}$ of transects and exploratory reconnaissance trails walked in the area. However, all chimpanzee observations made on these transects (direct sightings, vocalizations, discovered nests or scats) are shown as pink triangles and surveyed forest patches in which we did not put up camera traps are shown as gray dots. Shown as dotted lines are the Zémongo reserve as well as the part of the hunting zone Dembia that belongs to the Chinko drainage system are. (For interpretation of the references to color in this figure legend, the reader is referred to the web version of this article.)

collaboration with the Central African NGO "Chinko Project", of which we (TA and $\mathrm{RH}$ ) were cofounders, to protect an extensive tropical forest and savanna ecosystem in which evolutionary processes are chiefly driven by natural forces. Its location in central Africa makes the CNR a crucial stronghold for focal flagship species like the Eastern giant eland (Tragelaphus derbianus gigas), African wild dog (Lycaon pictus), lion (Panthera leo), African forest elephants (Loxodonta cyclotis), giant forest hog (Hylochoerus meinertzhageni), hippopotamus (Hippopotamus amphibius), Lelwel hartebeest (Alcelaphus buselaphus lelwel) and lowland bongo antelope (Tragelaphus eurycerus eurycerus). The area is currently managed by the NGO "African Parks Network" and is under way to become an official Faunal Reserve.

\subsection{Data collection}

We conducted extensive field surveys between January 2012 and December 2016 in a study area of approximately $12500 \mathrm{~km}^{2}$ within the CNR. In total, we set up camera traps at 597 distinct locations (Fig. 2) resulting in a total effort of 21,062 camera trap days, and walked reconnaissance transects totaling $>1750 \mathrm{~km}$.

We used 275 Bushnell camera traps (Trophy Cams 119436-119776), but also 40 Cuddeback Professional NoFlash (Model 1354) and 12 Reconyx HC500 HyperFire Semi-Covert IR. All camera traps were mounted on trees at about $40-60 \mathrm{~cm}$ above ground and least $3 \mathrm{~m}$ from the focal point to successfully capture both small (e.g. mice) as well as large animals (e.g. elephant). At each location, camera traps were put on animal path or near prominent structures like fallen trees or termite mounds to maximize encounter rate on a local scale and the angle to the path or structure was $45^{\circ}$ or less to increase detection rate of a moving target. No lure or bait was used, but some of the salt licks were stocked with minerals by the management to attract herbivorous animals from far away.

Given the remoteness of the area, most camera traps were placed on foot often far from camps in a demanding environment also frequented by poachers, rebels and illegal nomadic pastoralists. This not only imposed constraints in term of accessibility of certain areas, but also resulted in the loss or failure of $>25 \%$ of camera traps due to vandalism. However, we tried hard to stick to standardized protocols as follows: About half of the camera trap effort was used to uniformly survey particular areas using a grid approach to compile a complete inventory of larger mammals and larger ground birds in the area. The remaining camera trap effort was used to record focal species for census purposes (initially mainly leopards and Eastern giant elands) by placing them in hot spots or bonanzas with high detectability (salt licks, major animal paths and roads), or to cover special geographical and environmental features such as lakes.

In early February 2015, we discovered chimpanzees during a three month targeted expedition east of the Chinko River (Supplementary Fig. A1). Over the course of this survey, camera traps were run for two distinct sessions. In the first session (January 30th to March 21st), 38 camera traps were distributed across 37 locations within a minimum convex polygon of $333 \mathrm{~km}^{2}$ but with a kernel of higher density consisting of 28 camera traps in a polygon of $88 \mathrm{~km}^{2}$. Given 14 cameras were lost or failed, this session resulted in a total effort of 1085 camera trap days. In the second session (April 14th to 29th) we used 65 camera traps, of which eight were set up at each site where chimpanzees were detected in the first session and the remaining were used to extend the geographic range surveyed to the south and east. In total, the camera traps were set up at 60 distinct locations extending $44 \mathrm{~km}$ east-west and $11 \mathrm{~km}$ north-south within a minimum convex polygon of $447 \mathrm{~km}^{2}$. All 65 camera traps were collected after 2 to 14 days, of which two experienced technical failures. The limited survey effort and pronounced heterogeneity of observation time for this second session is a result of the remoteness and inaccessibility of the area that prevented us from collecting the camera traps in the same order they were set out. In summary, this session resulted in a total effort of 500 camera trap days (Supplementary Tables A1 and A2).

To locate chimpanzee nests, we walked $86.2 \mathrm{~km}$ of line transects with an average speed of $2.1 \mathrm{~km}$ per hour in closed canopy forest (CCF) patches of different sizes. While we stuck meticulously to the predefined straight line transects within forest patches, transects from multiple patches were combined in loops of reconnaissance trails to maximize the time spent in forests. In very large forest patches we sometimes had to change course to ensure we would be back at our camp before sunset. In the few cases a change of direction was necessary, the transect was broken in two segments and we did not include the $40 \mathrm{~m}$ (more than twice the detectability) between the segments in our analysis (see Supplementary Fig. A1 for an example). GPS coordinates of all transects were recorded using the software LOCUS Pro on a smartphone (Samsung Galaxy SII and Sony Xperia) and we used 
high resolution satellite imagery from Google Earth for navigation. For each nest encountered along the transects we recorded the exact location and measured the perpendicular distance to the transect and the nest height in meters using a Leica Rangemaster CRF 1600 or standard meter scale. We controlled for other nests after spotting nests from the transect. The age of every nest was estimated in days by trained and experienced local trackers (Bigoloko Gérmain Mongolo, Gbongbo Raymond and Gangbo Hervé) based on the decay of building material. These assistants were all former poachers of elephants and larger wildlife (including chimpanzees in case of Raymond) and were especially trained by the authors to conduct line transects and standing crop count surveys.

\subsection{Community structure, size and composition}

Long-term studies have shown that chimpanzees live in dynamic social structures made up of highly fluid parties which change composition and interact regularly with other parties of the same community (Boesch, 1996; Goodall, 1986; Nishida, 1979; Watts, 1998; Wrangham et al., 1996). While our relatively short period of observation does not enable any inference on these long-term dynamics of chimpanzees in the Eastern CAR, we described the temporary structure and composition as follows: First, we identified communities as groups of individuals that were foraging and nesting autonomously for up to several weeks in a confined geographic area in which we regularly found either direct (camera trap pictures, sightings or vocalizations) or indirect (fresh nests or scats) evidence for the presence of chimpanzees. Communities were considered separated if individuals were recorded concurrently (within $<5 \mathrm{~h}$ ) in two distinct geographic areas at least $5 \mathrm{~km}$ apart, which is above the assumed distance covered by chimpanzees within that time (Boesch and Boesch-Achermann, 2000). Second, we inferred a conservative minimum group size and composition by identifying individuals on camera trap pictures of a community based on i) morphological features such as fur color, scars, stature and facial features, ii) because they were recorded on the same picture or during a sequence of pictures of a group passing a camera trap, or iii) because they were recorded concurrently in distant locations. Third, we estimated lower and upper bounds on the size of the area used during the survey period as, respectively, the minimal convex polygon encompassing all direct and indirect observations such as camera trap pictures, nests, sightings and vocalizations, and a circle with a radius encompassing the area of the forest cluster within which the presence of chimpanzees cannot be excluded based on our survey.

\subsection{Chimpanzee density estimation}

Since most line transects were visited only once, we used standingcrop nest count (SCNC) methods based on distance sampling (Buckland et al., 2001) to estimate the abundance of weaned chimpanzees in the CNR (Tutin and Fernandez, 1984). While there are many SCNC methods available (Kühl et al., 2008; Plumptre and Reynolds, 1997a, 1996; Tutin and Fernandez, 1984), we chose here to follow (Plumptre and Reynolds, 1997b) by first inferring nest density $D_{n}$ using the software DISTANCE 6.2R1 (Thomas et al., 2010), from which we estimated weaned chimpanzee density $D_{c}$ as

$D_{c}=D_{n} / t r$

where $t$ is the mean lifetime of nests and $r$ the number of nests built per builder per day, for which we used several values from the literature to assess robustness. For the nest production rate we used i) $r=1.14$ as reported for three habituated wild chimpanzee communities in Tai National Park, Republic of Côte d'Ivoire (Kouakou et al., 2009) and ii) and $r=1.09$, a value often cited in the literature and reported from both the Budongo forest (Plumptre and Reynolds, 1997a) and the lowland tropical forest in northern Congo (Morgan et al., 2006). For the mean nest lifetime $t$ we evaluated 22 studies from 16 different locations across the whole species range of chimpanzees (Blom et al., 2001; Carvalho et al., 2013; Devos et al., 2008; Fleury-Brugiere et al., 2010; Ghiglieri, 1979; Hall et al., 1998; Hicks et al., 2014; Ihobe, 2005; Kouakou et al., 2009; Marchesi et al., 1995; Matthews and Matthews, 2004; Moyer et al., 2006; Ogawa et al., 2006; Plumptre and Reynolds, 1997a, 1996; Pruetz et al., 2002; Serckx et al., 2014; Stewart et al., 2011; Sugiyama et al., 1988; Sugiyama and Soumah, 1988; Tutin and Fernandez, 1984; Van Krunkelsven, 2001). We then considered the median estimate per location to obtain four different estimates used in this study: the median estimate of all ecotone locations matching our habitat (Lopé NP Gabon, Niokolo Koba NP Senegal, forest-savanna mosaic of western DRC, Ugalla Forest in Tanzania, Haut Niger NP in Guinea and Lagoas de Cufada Natural Park in Gambia, 140 days), the median estimate of all 16 locations (120 days), as well as $1.5 \times$ more and less than this global median (180 and 80 days, respectively). These values span a large range and are close to or higher than the rough estimate of the mean nest lifetime (78.22 days) we obtained from the estimated age of all observed nests.

We ran the inference both on individual nests as well as nest-groups, which we defined as a group of nests of the same age of which each is closer than a certain distance (nest-group distance, NGD) to at least one other nest of the same group. We used a NGD of $20 \mathrm{~m}$, as is frequently done in the literature (Kouakou et al., 2009), as well as a conservative NGD of $102 \mathrm{~m}$, which ensures that all nests of the same presumed age that we found in the same locality are considered as a single group (see below).

\subsection{Habitat preferences}

We used the software QGIS 2.4.0-Chugiak (QGIS Development Team, 2014) and Matlab R2014b to classify the land cover of the Eastern CAR at a resolution of $30 \times 30 \mathrm{~m}$ pixels into five major habitats: Closed Canopy Forest (CCF), Open Savanna Woodland, Dry Lakéré Grassland, Wet Marshy Grassland and Surface Water. The study region corresponds to the combined area of four Landsat images, but to obtain a high visibility despite cloud cover and smoke from fires, we retrieved twenty Landsat images taken between January and February (dry season) of 2014 and 2015. A supervised classification was performed with Matlab using six spectral bands (Red, Green, Blue, Near Infrared, Short-wave Infrared and Thermal Infrared), the Normalized Difference Vegetation Index (NDVI), altitude, slope, aspect derived from the digital elevation model SRTM-30m of the Shuttle Radar Topography Mission (Farr and Kobrick, 2000), and some morphological indicators (entropy and reconstruction). The remote sensing data were calibrated with observed ground truth based on surveys from 2012 to 2016 (mean Cohen's kappa of 0.91). We then used the resulting habitat map to assess the chimpanzee habitat preferences by comparing the habitat composition in circular areas around observed nest sites (one location per nest group with NGD $102 \mathrm{~m}$ ) with that around 5000 random locations chosen within CCF in the region inhabited by chimpanzees. We then calculated the distance.

$\mathrm{T}=\mathrm{d}_{1}+\mathrm{d}_{2}-2 * \mathrm{~d}_{\mathrm{b}}$

where $d_{1}, d_{2}$ and $d_{b}$ are the average euclidean distances between habitat composition vectors for respectively all pairs of true nest sites $\left(\mathrm{d}_{1}\right)$, all pairs of random locations $\left(\mathrm{d}_{2}\right)$ and all pairs with one vector from each group $\left(\mathrm{d}_{\mathrm{b}}\right)$. Significance of this distance was then assessed using $10^{5}$ random permutations of group labels. This analysis was repeated at ten different biologically meaningful scales $(0.001,0.005,0.020,0.078$, $0.31,1.25,5,20,80$ and $250 \mathrm{~km}^{2}$ ) spanning from the area comprising all nests of a single group up to the assumed home range of chimpanzee communities in savanna habitat (Ogawa et al., 2006; Pruetz and Lindshield, 2012). 


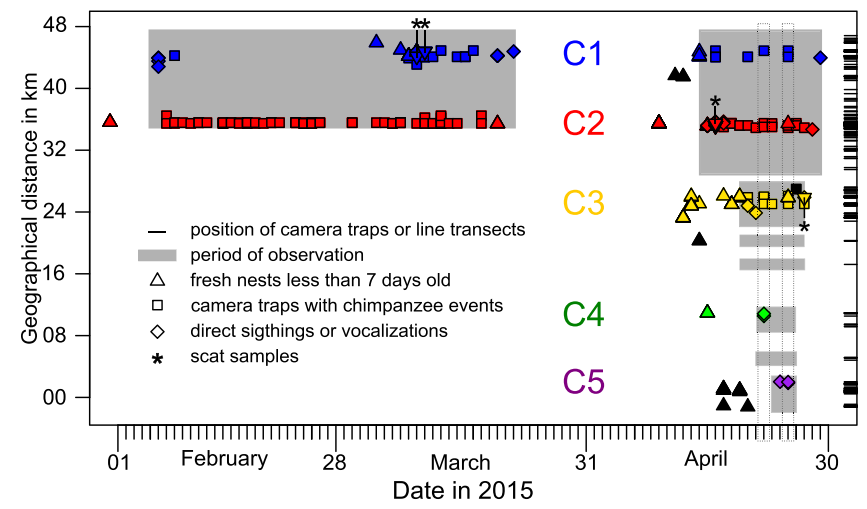

Fig. 3. Geographic and temporal distribution of camera trap events (squares), direct sightings or vocalizations (diamonds) as well as fresh nests less than seven days old (triangles placed at estimated time of construction) of chimpanzees. The geographical distance is measured in $\mathrm{km}$ from the most southeastern observation towards northwest. Lines at the right side indicate positions of camera traps and line transects. Gray lines show periods when camera traps were active or line transects in the area conducted. Observations classified to five putative communities ( $\mathrm{C} 1$ to $\mathrm{C5}$ ) are indicated in color and those not assigned in black. Dotted boxes around indicate simultaneous observations from at least four different communities. Scat samples were collected at the four sightings marked with an asterisk.

\subsection{Microsatellite genotyping}

From March to April 2015 we sampled 16 fresh chimpanzee scats from a few minutes up to a few hours after deposition. The scats were sampled at six different sites which form three clusters 8.5, 9.2 and $18.2 \mathrm{~km}$ apart that each represents one of the communities outlined below (Fig. 3). Either the surface of large solid scats, or entire droplets of soft feces, were transferred with a wooden stick into a TPP Cryo tube 50 (89050, PP) or a $15 \mathrm{ml}$ TPP Centrifuge tube $(91,115$, PS) which had been sterilized by radiation, was free from pyrogens, DNA, RNA, DNases and RNases and contained analytical ethanol (Honeywell, absolute, semiconductor grade, $\geq 99.8 \%$ vol.). Prior and post sampling, the tubes were stored at ambient temperature but always protected from direct sunlight.

All samples were collected and exported with official authorisation of the government of the Central African Republic. Five months after collection, fecal samples were dried on silica for $48 \mathrm{~h}$ (Nsubuga et al., 2004) and DNA was extracted using the QIAamp Stool kit (QIAGEN) with slight modifications and genotyped at 11 microsatellite loci (D5s1457, D10s676, D5s1470-PIG, D4s1627, D7s817-F2, D11s2002R2, D3s3038, D3s2459, D1s1656, D7s2204 and D2s1326-R2) as described elsewhere (Arandjelovic et al., 2011, 2009). While two scat samples turned out to be mixtures of multiple individuals (likely mother and infant), the remaining samples could be assigned to 11 distinct individuals.

\subsection{Inferring population structure}

We compared our chimpanzees samples to other representative populations of Central (P. t. troglodytes) and Eastern chimpanzees (P. $t$. schweinfurthii) from different geographic regions and roughly equally distant to the CNR (Fig. 1) that were typed at overlapping sets of microsatellite markers. We first combined our data with that of three populations of Central chimpanzees from Loango in Gabon (Arandjelovic et al., 2011), Lobéké in Cameroon and Nouabalé-Ndoki in the Republic of Congo (Fünfstück et al., 2015) and one population of Eastern chimpanzees from Budongo-Bugoma in Uganda (McCarthy et al., 2015) and used the eight microsatellite loci D10s676, D5s1470PIG, D4s1627, D7s817-F2, D11s2002-R2, D3s3038, D3s2459 and D7s2204 that were typed in all populations. In a second set of analyses we added two additional populations of Eastern chimpanzees from
Ugalla in Tanzania (Moore and Vigilant, 2013) and Gishwati in Rwanda (Chancellor et al., 2012). Given substantial mismatch between microsatellite loci used by these studies, these analyses were limited to the three microsatellite markers D5s1470-PIG, D7s817-F2 and D11s2002R2. In both cases, we selected only individuals without missing data, but limited the data set to 14 individuals per population to maintain balanced sample sizes. We did this as a precaution, as in case of uneven sampling, distinct subpopulations represented by only few samples tend to cluster together while individuals from extensively sampled and panmictic subpopulations tend to be split when inferring population structure from genetic data (Puechmaille, 2016).

We used the software STRUCTURE Version 2.3.4 (Pritchard et al., 2000) to infer the genetic structure of the chimpanzees and to assign our samples to the correct subspecies. In all cases, STRUCTURE was run multiple times to check for convergence and always with a burn-in of $10^{5}$ steps and $5 \cdot 10^{5}$ steps during data collection and used the delta $\mathrm{K}$ method (Evanno et al., 2005) to identify the most likely number of clusters K. Given the generally low number of markers, we decided to use a non-admixture model (individuals are exclusively from one population or another) with priors on the sampling location. This model is appropriate for studying fully discrete populations and is often more powerful than the admixture model at detecting subtle structures (Pritchard et al., 2010). However, to test the robustness of the obtained results, we also conducted all analyses using the default admixture model.

\section{Results}

\subsection{Current distribution}

Despite extensive camera trapping (21062 camera trap days) and $1750 \mathrm{~km}$ of walked transects, we have not found any evidence for chimpanzees in the CNR west of the Chinko River. During expeditions to the east of the Chinko River, however, ample evidence of chimpanzees was discovered both with camera traps and on walked transects, suggesting that chimpanzees are rather abundant in that area. This is illustrated in Fig. 2 where we plot all locations at which direct or indirect chimpanzee sightings were recorded, as well as the remaining of the 597 distinct locations that were surveyed with camera traps in 2012-2016 (with or without chimpanzees records). Consequently, our data strongly suggest that presently no significant population exists west of the Chinko River, but a sizeable population between the Chinko and Vovodo Rivers as well as further east.

\subsection{Community structure and composition}

While our short period of observation did not allow us to draw any detailed conclusions regarding the complex long-term community structure of chimpanzees, the geographic and temporal distribution of direct and indirect chimpanzee observations on transects and by camera traps suggests that the area was inhabited by multiple distinct social groups (henceforth referred to as communities) during the surveyed dry season. In total we identified at least five communities (C1-C5, Fig. 3, Supplementary Fig. A1, Supplementary text) that each inhabited a distinct and confined geographic area in which they were recorded regularly either directly or indirectly. Such recordings often occurred concurrently for the different communities (35 pairs within $5 \mathrm{~h}$, between $7.6 \mathrm{~km}$ and $43.0 \mathrm{~km}$ and on average $14.4 \mathrm{~km}$ apart, Fig. 3, Supplementary Fig. A1). In addition, we could individually identify 22 chimpanzees based on morphological features and all of these individuals were recorded in the area assumed to be inhabited by their community only.

A sufficient number of photographs (1656) were recorded for communities C1, C2 and C3 to infer minimal group sizes and some information regarding their composition. We estimated that Community C1 consisted of at least 19 individuals: four adult males, six 
adult females, six juveniles and three infants. Community C2 consisted of at least 29 individuals: nine adult males, nine adult females, one subadult, four juveniles and six infants. Finally, Community C3 consisted of at least 14 individuals: four adult males, four adult females, four juveniles and two infants. The presence of juveniles and infants in all communities suggests that these were successfully reproducing. This is further supported by camera trap events of multiple adult females carrying infants (two, six and one females in C1, C2 and C3, respectively) or being in estrus (one and two in $\mathrm{C} 1$ and $\mathrm{C} 2$, respectively).

Interestingly, and despite the heterogeneous landscape, all identified chimpanzee communities used rather limited areas, at least over the course of the several-week-long survey period. This is best illustrated with Community C2, which we recorded regularly but only within a minimum convex polygon of $3.5 \mathrm{~km}^{2}$. This area is situated in a major closed canopy forest (CCF) cluster of about $10.5 \mathrm{~km}^{2}$ that we surveyed with nine camera traps and 14 additional traps distributed around, within $6.5 \mathrm{~km}$ from the observed activity center (Supplementary text). When also considering older nests and more stringently accounting for areas not densely surveyed, the territory of Community $\mathrm{C} 2$ was $<30 \mathrm{~km}^{2}$ during the survey period. While our data for Community $\mathrm{C} 1$ do not allow for an equally accurate territory estimate, all camera trap records, direct observations and fresh nests from that community are from a forested area of only $9.6 \mathrm{~km}^{2}$ using a minimum convex polygon. However, this community likely also used a neighbouring forest patch regularly, as i) we did not record any chimpanzees in the aforementioned area for up to 28 consecutive days, ii) both fresh and old nests were found in both forest patches and iii) a camera trap located in open savanna woodland in between these patches recorded a large number of individuals moving through multiple times in both directions (Supplementary Fig. A3). Conservatively estimated, the territory of Community $\mathrm{C} 1$ was thus about $40 \mathrm{~km}^{2}$ containing about $15 \mathrm{~km}^{2}$ of suitable habitat (CCF, see below). The records of the other communities do support territories of similar sizes, albeit with much larger uncertainty as a result of the limited data available for those (Supplementary text).

\subsection{Chimpanzee density}

We conducted standing-crop nest count (SCNC) surveys in the CNR to estimate local chimpanzee densities. Our survey effort was $86.2 \mathrm{~km}$ of transect walked in CCF, which constitutes the only habitat used by chimpanzees for nest building according to our observations (see below) and other reports from ecotone habitats (Marchesi et al., 1995). We counted a total of 384 nests and used DISTANCE 6.2 to estimate chimpanzee nest density in our study region from these data based on the half-normal key detection model with lowest Akaike information criterion (Buckland et al., 2010, 2001). Under this model, we estimate a density of weaned chimpanzees in CCF of 0.81 (95\% confidence interval 0.48 to 1.37 ) when using a nest production rate of $r=1.14$ and a mean nest lifetime of 140 days (Table 1 ). Repeating the analysis with alternative values frequently used in the literature resulted in estimates ranging from 0.63 to 1.43 weaned chimpanzees per $\mathrm{km}^{2}$ (Table 1 ).

To further assess the robustness of our estimate, we also inferred densities using the "cluster" approach in DISTANCE. Such estimates are highly dependent on the definition of nest-groups and the estimate of their sizes. To obtain a conservative estimate, we measured for each nest the distance to the closest other nest for ten independent sites with fresh nests ( $<7$ days). This resulted in distances from 5 to $102 \mathrm{~m}(38 \mathrm{~m}$ on average), based on which we defined a nest-group distance (NGD) of $102 \mathrm{~m}$, which ensured that each of these localities was treated as a single nest group. Applying this definition to the full data resulted in 139 nest-groups that ranged from 1 to 21 in size and consisted of 2.8 nests on average. From this data we estimated a density of 115.01 nests $/ \mathrm{km}^{2}$, which translates to a weaned chimpanzee density in CCF of 0.72 (95\% confidence interval 0.46 to 1.13$)$ when using a nest production rate of $r=1.14$ and a mean nest lifetime of 140 days (Table 1 ).
Other definitions of nest-groups are frequently used, however. Using a much smaller NGD of $20 \mathrm{~m}$ (Kouakou et al., 2009), we counted a total of 170 nest-groups of 2.26 nests on average (median 1 ), which resulted in a $25 \%$ higher weaned chimpanzee density of 0.90 per $\mathrm{km}^{2}(95 \%$ confidence interval 0.55 to 1.45 ) when using a mean nest lifetime of 140 days and a nest production rate of 1.14 , as above (Table 1 ). It is important to note, however, that these estimates assume an equal rate of decay for all nests in a group, but differential decay was apparent from our data as groups older than two weeks consisted of only 2.6 nests on average, while groups younger than seven days consisted of 3.3 nests on average.

In conclusion, all alternative ways of estimating weaned chimpanzee density in the surveyed region fall well within the confidence interval of our most trusted estimate of around 0.81 weaned chimpanzees per $\mathrm{km}^{2}$ of CCF, which was based on single nests and parameter values most suited for the surveyed habitat. Based on the community composition estimates from our camera trap survey, we estimate the proportion of nest-builders in a community to be about 0.83 and 0.71 when assuming that all individuals except infants build their own nest or only half of the juveniles build visible nests, respectively. This estimated proportion of nest-builders from Chinko falls within the values mentioned in the literature for chimpanzees and bonobos (Kühl et al., 2008). The total density of chimpanzees in the study region thus amounts to about 1.06 chimpanzees per $\mathrm{km}^{2}$ of CCF.

\subsection{Population size}

We next estimated the total population size of chimpanzees in the part of the CNR occupied by chimpanzees. This region, corresponding to the former hunting zone Vovodo Chinko 41, is bounded by the Chinko River in the west and Vovodo in the east, which also constitutes the current eastern boundary of the CNR itself. Within this region, we estimated a total area of $1120 \mathrm{~km}^{2}$ of CCF from our habitat map inferred at a spatial resolution of $30 \times 30 \mathrm{~m}$ from calibrated LANDSAT data revealed. Based on the estimated weaned chimpanzee density of 0.81 per $\mathrm{km}^{2}$ of CCF reported above, we thus expect around 907 (95\% confidence interval 538 to 1534) weaned chimpanzees to inhabit the CNR, which amounts to about 1200 chimpanzee individuals in total. Given that the total area of the eastern CNR between the rivers Chinko and Vovodo is $3240 \mathrm{~km}^{2}$, the overall weaned chimpanzee density in this region would be 0.28 individuals per $\mathrm{km}^{2}$. But we stress that this value is of limited use since the abundance of CCF is highly heterogenous in the Eastern CAR and thus the same is almost certainly true of the chimpanzee density.

We used a second approach to estimate chimpanzee population size in CNR which is independent of nest count techniques (Kühl et al., 2008). Based on our observed number of chimpanzee communities and estimated territory sizes of under $30 \mathrm{~km}^{2} \mathrm{CCF}$, as well as the distribution of suitable CCF habitat, a total of about 45 independent chimpanzee communities seem plausible within the CNR (Supplementary Fig. A2). Given that we observed about 15 weaned individuals per group, we arrive at an estimate of approximately 675 weaned chimpanzees. While admittedly rough (Newton-Fisher, 2003), this estimate nonetheless falls well within the range estimated above, thus confirming the plausibility of the obtained conclusions.

\subsection{Habitat preferences}

While chimpanzees in other ecotone regions were found to occasionally nest in woodland savanna (Baldwin et al., 1982; Hicks et al., 2014; McCarthy et al., 2015; Moore and Vigilant, 2013; Ogawa et al., 2007; Pruetz et al., 2008), all 406 chimpanzee nests found in this study were located in CCF, as was also reported for the ecotone of Republic of Côte d'Ivoire (Marchesi et al., 1995). In the CNR, chimpanzees further favor extensive CCF habitat also around their nest sites. Indeed, a circular area around the 154 unique nest sites (NGD of $20 \mathrm{~m}$ with no 
Table 1

SCNC distance methods and parameters used to infer the density of chimpanzees in the study area. A total of 384 nests were detected on $86.2 \mathrm{~km}$ line transect in CCF. The best fitting parameters for the study area are set and all changed settings are indicated with gray background.

\begin{tabular}{lcccccccc}
\hline Model & ESW m & Ng & Sg & Mg & ECS & r & t days & Dc weaned (95\% CI) \\
\hline Single nest & 17.08 & 384 & $(-)$ & $(-)$ & $(-)$ & 1.14 & 140 & $0.81(0.48-1.37)$ \\
Single nest & 17.08 & 384 & $(-)$ & $(-)$ & $(-)$ & 1.14 & 80 & $1.43(0.85-2.40)$ \\
Single nest & 17.08 & 384 & $(-)$ & $(-)$ & $(-)$ & 1.14 & 120 & $0.95(0.56-1.60)$ \\
Single nest & 17.08 & 384 & $(-)$ & $(-)$ & $(-)$ & 1.14 & 180 & $0.63(0.38-1.07)$ \\
Single nest & 17.08 & 384 & $(-)$ & $(-)$ & $(-)$ & 1.09 & 140 & $0.85(0.51-1.44)$ \\
Cluster $100 \mathrm{~m}$ & 20.46 & 139 & 2 & 2.76 & 2.92 & 1.14 & 140 & $0.72(0.46-1.13)$ \\
Cluster $20 \mathrm{~m}$ & 17.45 & 170 & 1 & 2.26 & 2.54 & 1.14 & 140 & $0.90(0.55-1.45)$ \\
\hline
\end{tabular}

overlap) contained significantly more CCF than the same area around random CFF locations within the region inhabited by chimpanzees, regardless of scale (Fig. 4, $\mathrm{p}<10^{-5}$ at all scales).

\subsection{Genetic comparison}

We obtained good quality genotypes of 11 individuals at $11 \mathrm{mi}$ crosatellites from fresh chimpanzee feces collected in the field. The samples represent three of the putative groups identified above (Communities C1, C2 and C3). Since there is no standard set of microsatellites used and since the comparison of alleles identified by different research groups is difficult, we restricted our comparison to individuals from one Eastern (Budongo-Bugoma, $\mathrm{n}=14$, (McCarthy et al., 2015) and three Central chimpanzee populations (Arandjelovic et al., 2011; Fünfstück et al., 2015)Loango, $\mathrm{n}=12$, Lobéké, $\mathrm{n}=12$ and Ndoki, $n=14$, (Arandjelovic et al., 2011; Fünfstück et al., 2015) and also to eight loci for which we were confident in matching alleles between studies. Despite the limit number of markers, all analyses conducted with STRUCTURE consistently assigned the CNR individuals to an Eastern chimpanzee cluster both at the preferred $\mathrm{K}=2$ and any higher K (Fig. 5). Notably, the central populations first form their own clusters in the case of $\mathrm{K}=4$, although the populations of Lobéké and Ndoki were as close as $145 \mathrm{~km}$. This robust grouping of the CNR chimpanzees with Eastern chimpanzees was further confirmed in additional analyses (Supplementary Fig. A4) with a reduced set of only three loci but two additional Eastern chimpanzee populations from Gishwati and Ugalla (Chancellor et al., 2012; Moore and Vigilant, 2013). We also note that the clustering of our CNR samples with those from Budongo-Bugoma is not due to physical proximity since the CNR is about equally distant from Nouabale-Ndoki, the closest Central chimpanzee population included in our analysis (approx. $950 \mathrm{~km}$ ). In addition, all Central chimpanzee populations included are geographically much closer to each other (145-835 km) but are identified as individual clusters in our STRUCTURE analysis at lower K's than Budongo/Chinko. Finally we note that all results are also confirmed, albeit with more noise, when performing the analysis with the admixture ancestry model (data not shown).

\section{Discussion}

Here we report the presence of a viable population of Eastern chimpanzees (Pan troglodytes schweinfurthii) in the eastern part of the Central African Republic (CAR). Their location at the northern limit of the chimpanzee distribution and their heterogeneous habitat in the forest-savanna ecotone make them an ecologically relevant population for the long term survival of the species (Plumptre et al., 2010). Surprisingly, the population appears confined to habitats east of the Chinko River as no evidence for chimpanzees was found west of that river despite considerable survey effort. This geographic distribution is in contrast to recent distribution models that predicted much more favorable environmental conditions west of the Chinko River and classified most parts of Eastern CAR and the entire eastern part of CNR as unsuitable (Junker et al., 2012; Plumptre et al., 2010). At least $25000 \mathrm{~km}^{2}$ (27\%) (IUCN SSC A.P.E.S. database, Drexel University and Jane Goodall Institute, 2016), or $57290 \mathrm{~km}^{2}$ (62\%) (Plumptre et al., 2010) of the supposed chimpanzee distribution in Eastern CAR as estimated by the International Union for the Conservation of Nature (IUCN) and the Wildlife Conservation Society (WCS), respectively, is most likely not or no longer occupied by chimpanzees. Our study thus showcases some limitations of relying solely on remote sensing data to

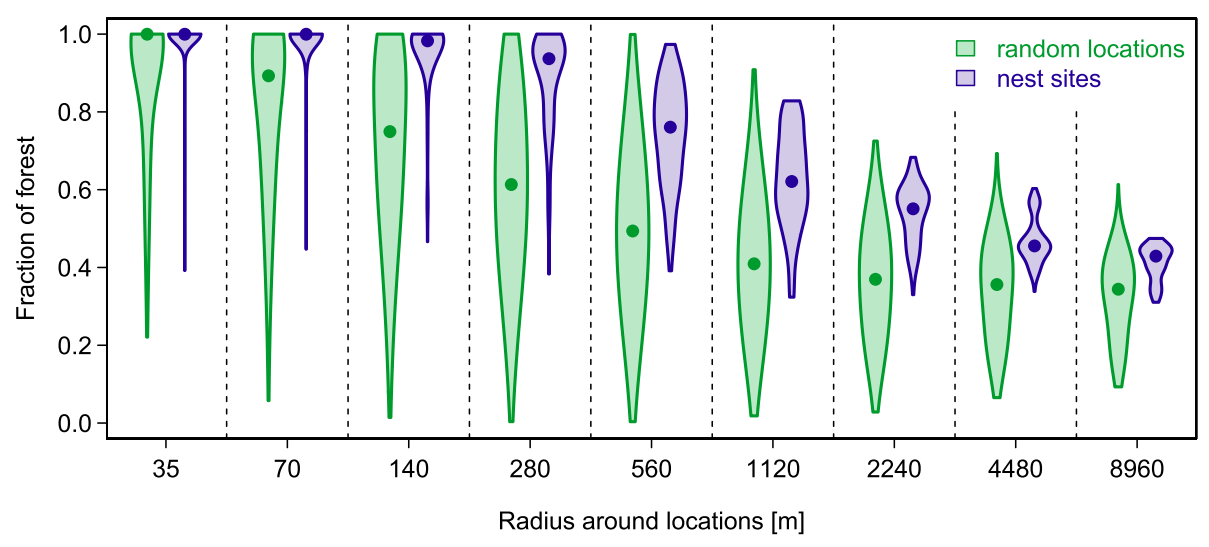

Fig. 4. Fraction of CCF habitat (median and density distribution) around all 154 unique nest sites (NGD of $20 \mathrm{~m}$ that do not overlap, purple) and 5000 random CCF locations (green) at different scales. All comparisons were highly significant at $\mathrm{p}<10^{-5}$ when using a permutation test. (For interpretation of the references to color in this figure legend, the reader is referred to the web version of this article.) 


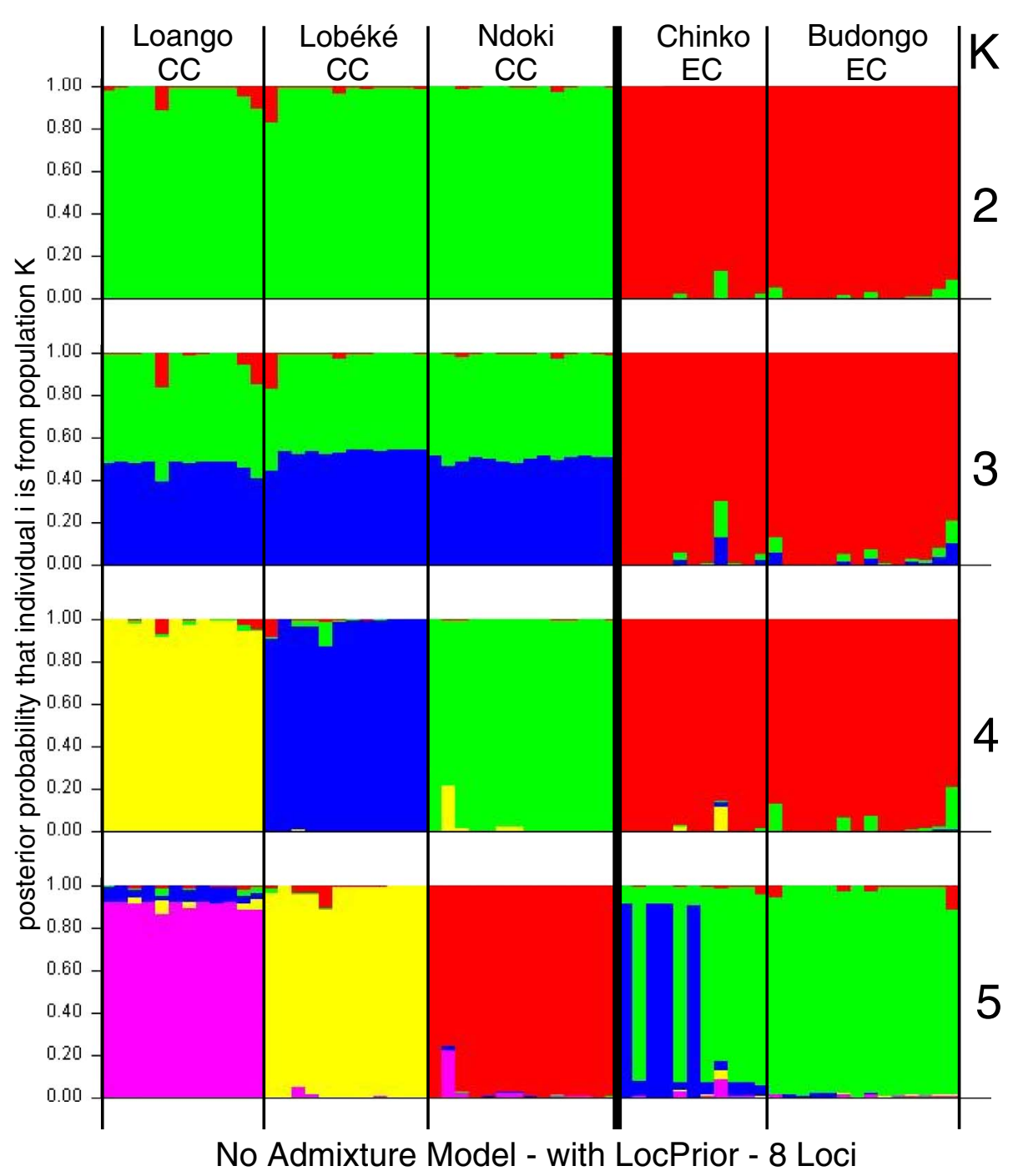

Fig. 5. Structure plots indicating affiliations of genotypes from 5 different populations. Loango, Lobéké and Nouabale-Ndoki represent central chimpanzees, BudongoBugoma is an eastern population. Chinko genotypes cluster with Budongo for several $\mathrm{K}$ values indicating that this population belongs to supposed eastern subspecies P.t. schweinfurthii. predict distributions of endangered species in regions for which limited or no training data is available, and therefore illustrates the necessity of extensive field surveys to accurately assess population density in remote and scientifically underrepresented areas. This is especially relevant for species like chimpanzees that may adapt their lifestyle to diverse environmental conditions but are heavily affected by anthropogenic disturbances.

\subsection{Long term conservation of chimpanzees}

The revised distribution map of chimpanzees in the Eastern CAR necessitates a reevaluation of the chimpanzee conservation strategy in the region. Being currently the only area under conservation management, the CNR will likely play a crucial role in any such action plan. Within its boundary we estimated the presence of about 900 chimpanzees. On their own they are at the lower limit of what constitutes a viable population, for which often a few thousand adult individuals are needed to ensure long-term persistence (Reed et al., 2003; Traill et al., 2007/9). However, adjacent areas connected via continuous habitat suggest that the population of chimpanzees beyond the limits of the reserve is much larger. Indeed, our own observations combined with information from big game hunters, local trophy hunting operators, local poachers and Central African researchers (Ndallot et al., 2015) suggest that chimpanzees were present in 2015 in the adjacent, designated but unmanaged Zémongo reserve (Roulet et al., 2007) as well as in the hunting zones Daradou 42, Djema 43 and the western part of
Dembia 49 belonging to the drainage system of the Chinko River (see Supplementary Fig. A1 for a map). All these zones are already designated as areas to maintain wildlife and contain $3348 \mathrm{~km}^{2}$ of CCF in total, which likely harbour $\sim 2700$ chimpanzees at the density estimated above. Together with the CNR, these could form a continuous conservation area inhabited by $\sim 3600$ chimpanzees. Given the relatively low human density and abundant CCF habitat, several thousand additional chimpanzees may occur in the vast hunting zones further to the east, but no reliable information about current chimpanzee presence or the general status of wildlife is currently available for that region.

In conclusion, Eastern CAR appears to be an important stronghold of Eastern chimpanzees in the Central African forest-savanna ecotone, as was previously recognized (Plumptre et al., 2010). In order to ensure the long-term viability of this population, a dedicated conservation action plan is urgently needed to i) enlarge the currently protected area, ii) reduce the ongoing killing of chimpanzees by local and international poachers and iii) limit the destruction of habitat by nomadic pastoralists from the Sahel and through illegal mining. Local employees managing the CNR report that chimpanzee meat is frequently sold and orphans often kept in towns of the Eastern CAR. While most poachers claim these chimpanzees to originate from the Democratic Republic of Congo, CNR rangers recently confiscated dead chimpanzees transported on a logboat on the Chinko River $100 \mathrm{~km}$ away from the next settlement or road, suggesting that poaching is a major threat also in remote areas of the CNR. In line with this, chimpanzees directly observed during our 
field work were invariably extremely stressed and tried to leave as quickly as possible, sometimes even leaving their screaming juveniles or isolated mothers with infants behind. Such behavior was previously connected with hunting pressure in similar habitat (Hicks et al., 2012). Interestingly, at locations where chimpanzees were present, our camera traps recorded chimpanzees already short after installation (32\% within two, $82 \%$ within seven days). This suggests that chimpanzees return to productive areas very quickly after disturbance, maybe as a result of the generally high level of human disturbance in the area. Our field observations indeed showed that nomadic pastoralists were omnipresent during the dry season in all visited regions of the CNR (their presence was recorded in every $100 \mathrm{~km}^{2}$ surveyed), and fire monitoring of the Chinko Project suggest they also regularly use the area east of the Vovodo River, despite the fact that the CNR is one of the most remote areas on the planet and its natural vegetation is still virtually pristine. However, the massive influx of herders mainly from Darfur, Sudan (Roulet et al., 2007; Tidjani, 2015) is very recent (Henriot, 2014; Mararv, 2015). Many of their behaviors have a negative impact on the natural habitat and wildlife, i.e. cutting corridors through forests, burning down entire forest patches, debarking large tree stands or cutting down major trees with bee nests (Tidjani, 2015). Illegal mining further threatens fragile bodies of surface water and dramatically increases local poaching in western parts of the CNR, although its impact is currently low in the east where chimpanzees occur.

\subsection{Ecological considerations}

Our analyses suggest that the chimpanzees in the Eastern CAR are true forest dwellers that cross savanna habitat to reach other forest patches, but neither for nesting nor foraging. All our observations are from the dry season, but the complete absence of older nests in the open savanna woodland suggest that this habitat was also not frequently used during the highly productive wet season that concluded only two month prior to our survey period. The observed minimum territory of about $30 \mathrm{~km}^{2}$, with kernels as small as $3.5 \mathrm{~km}^{2}$, indicates that forest patches in Eastern CAR provide a local abundance of food resources. Indeed, such small or smaller territory sizes are only reported from highly productive humid forests (Amsler, 2010; Chapman and Wrangham, 1993; Kouakou et al., 2011; Morgan et al., 2006; NewtonFisher, 2003) and territories in savanna-woodland habitats tend to be much larger (Ogawa et al., 2006; Pruetz and Lindshield, 2012).

An open and somewhat puzzling question is why chimpanzees do not occur west of the Chinko River, especially since we did not observe any major difference in the abundance of other wildlife or disturbances on the different sides of the Chinko river. Since the historical data is very imprecise and often not well described, it may indeed be that the few reports of chimpanzees in the west were assigned to incorrect locations and chimpanzees never actually occurred in that area. However, given the large patches of forests in the west and the fact that the Chinko River can easily be crossed during the dry season (personal observation), this appears unlikely. But it also appears unlikely that chimpanzees in the west were poached to extinction in recent times since that area is much less accessible by boat or by road than the eastern part where chimpanzees seem to occur at considerable density. The most likely explanation may thus be that chimpanzees west of the Chinko River went extinct in historical times and, being inefficient colonizers (Goodall, 1986; Goossens et al., 2005; Kawanaka and Kenji, 1984; Langergraber et al., 2014; Mitani et al., 2002; Nishida, 1983; Teleki et al., 1976; Wilson and Wrangham, 2003), never reclaimed the western part. The omnipresence of artifacts (especially pottery fragments but also isolated mango trees or oil palms) of abandoned villages as well as the abundance of locations mentioned on old maps and historical texts (Coquery-Vidrovitch, 1972) suggest that the human population density in the currently uninhabited western part of the CNR may have been much higher in the past. This may have led to the local extinction of chimpanzees both through elevated hunting pressure and environmental degradation due to farming and timber production, in combination with global climate changes and the depletion of elephants as ecosystem engineers. Satellite images as well as our observations in the field indeed indicate that large parts of the forests west of the Chinko River are secondary successional forests in former savanna woodland.

\section{Conclusion}

Without proper field surveys, important populations for conservation of even charismatic mammals may easily be neglected, resulting in misguided conservation research and planning. Here we report the presence of a sizeable but threatened population of Eastern chimpanzees (Pan troglodytes schweinfurthii) in the savanna - forest ecotone of the eastern part of the Central African Republic. In contrast to predictions based on habitat considerations, this population currently only inhabits the closed canopy forests east of the Chinko River. As a result, only a fraction of the Chinko Nature Reserve is currently inhabited by chimpanzees, the only area under conservation management in the region. The long-term conservation of this ecologically important population critically depends on 1) the extension of the protected zones to include adjacent areas already designed for nature conservation but are not yet actively managed, and 2) the implementation of a conservation action plan to avert the threats posed by poaching, mining and the massive influx of pastoralists from the Sahel during the dry season.

Supplementary data to this article can be found online at http://dx. doi.org/10.1016/j.biocon.2017.06.031.

\section{Author contributions}

T.A. and D.W. conceived of the study and data collection. T.A. and S.G. carried out the field survey. T.A. and D.W. did all the analysis and wrote the first draft of the manuscript. E.R, T.A. and S.J. developed the habitat map, L.V., A.H. and M.A generated the microsatellite data. All authors edited and contributed to the writing.

\section{Acknowledgments}

We are grateful to our collaborators in the Central African Republic, especially the very experienced trackers Bigoloko Gérmain Mongolo, Gbongbo Raymond and Gangbo Hervé who supported this work with their vast knowledge about the bush and its wildlife. We thank the government of the Central African Republic for permission to conduct fieldwork and export permits, especially Ndallot Olobanda Jérémie, Directeur de la Faune et des Aires Protégées for his generous support. Special thank goes to the Chinko Project, especially David Simpson for his tireless effort, the African Parks Network and all their diligent collaborators for their great support and courtesy. This scientific work and research in general in the CNR was generously financially supported by Panthera, Basler Stiftung für Biologische Forschung and many private sponsors.

\section{References}

Adler, R.F., Huffman, G.J., Alfred, C., Ralph, F., Ping-Ping, X., John, J., Bruno, R., Udo, S., Scott, C., David, B., Arnold, G., Joel, S., Philip, A., Eric, N., 2003. The version-2 global precipitation climatology project (GPCP) monthly precipitation analysis (1979-present). J. Hydrometeorol. 4, 1147-1167.

Amsler, S.J., 2010. Energetic costs of territorial boundary patrols by wild chimpanzees. Am. J. Primatol. 72, 93-103.

Arandjelovic, M., Guschanski, K., Schubert, G., Harris, T.R., Thalmann, O., Siedel, H., Vigilant, L., 2009. Two-step multiplex polymerase chain reaction improves the speed and accuracy of genotyping using DNA from noninvasive and museum samples. Mol. Ecol. Resour. 9, 28-36.

Arandjelovic, M., Head, J., Rabanal, L.I., Schubert, G., Mettke, E., Boesch, C., Robbins, M.M., Vigilant, L., 2011. Non-invasive genetic monitoring of wild central chimpanzees. PLoS One 6, e14761.

Baldwin, P.J., McGrew, W.C., Tutin, C.E.G., 1982. Wide-ranging chimpanzees at Mt. Assirik, Senegal. Int. J. Primatol. 3, 367-385. 
Blom, A., Allard, B., Jean, Y., Prins, H.H.T., 2004. Status of the protected areas of the Central African Republic. Biol. Conserv. 118, 479-487.

Blom, A., Almasi, A., Heitkonig, I.M.A., K, J.-B., Prins, H.H.T., 2001. A survey of the apes in the Dzanga-Ndoki National Park, Central African Republic: a comparison between the census and survey methods of estimating the gorilla (Gorilla gorilla gorilla) and chimpanzee (Pan troglodytes) nest group density. Afr. J. Ecol. 39, 98-105.

Boesch, C., 1996. Social grouping in Taï chimpanzees. In: McGrew, W.C., Marchant, L.A., Nishida, T. (Eds.), Great Ape Societies. Cambridge University Press, Cambridge; UK, pp. 101-113.

Boesch, C., Boesch-Achermann, H., 2000. The Chimpanzees of the Taï Forest: Behavioural Ecology and Evolution. Oxford University Press.

Boulvert, Y., 1986. Carte Phytogeographique République Centrafricaine. ORSTOM Nº104. pp. $1-138$.

Buckland, S.T., Anderson, D.R., Burnham, K.P., Laake, J.L., Borchers, D.L., Thomas, L., 2001. Introduction to Distance Sampling: Estimating Abundance of Biological Populations. Oxford University Press, Oxford; New York.

Buckland, S.T., Plumptre, A.J., Len, T., Rexstad, E.A., 2010. Design and analysis of line transect surveys for primates. Int. J. Primatol. 31, 833-847.

Butynski, T.M., 2001. Africa's great apes. In: Beck, B.B., Stoinski, T.S., Hutchins, M., Maple, T.L., Norton, B., Rowan, A., Stevens, E.F., Arluke, A. (Eds.), Great Apes \& Humans: The Ethics of Coexistence. Smithsonian Inst Pr, Washington DC, pp. 3-56.

Caldecott, J.O., Miles, L., 2005. World Atlas of Great Apes and Their Conservation. Univ of California Press.

Carvalho, J.S., Marques, T.A., Luis, V., 2013. Population status of Pan troglodytes verus in Lagoas de Cufada Natural Park, Guinea-Bissau. PLoS One 8, e71527.

Chancellor, R.L., Kevin, L., Sergio, R., Rundus, A.S., Linda, V., 2012. Genetic sampling of unhabituated chimpanzees (Pan troglodytes schweinfurthii) in Gishwati Forest Reserve, an isolated forest fragment in Western Rwanda. Int. J. Primatol. 33, 479-488.

Chapman, C.A., Wrangham, R.W., 1993. Range use of the forest chimpanzees of Kibale: implications for the understanding of chimpanzee social organization. Am. J. Primatol. 31, 263-273.

Cmap, P.D., NOAA, 2012. Analysis of African Precipitation and Surface Temperature [WWW Document]. Earth System Research Laboratory - Physical Science Division (URL http://www.esrl.noaa.gov/psd/people/brant.liebmann/data/africa-echam5/ africa-echam5.html (accessed 16)).

Coquery-Vidrovitch, C., 1972. Le Congo au temps des grandes compagnies concessionnaires 1898-1930. Paris-La Hay, Mouton. 1. pp. 750.

The diversity of life in African freshwaters: under water, under threat. In: Darwall, W.R.T., Smith, K.G., Allen, D.J., Holland, R.A., Harrison, I.J., Brooks, E.G.E. (Eds.), An Analysis of the Status and Distribution of Freshwater Species Throughout Mainland Africa. IUCN, Cambridge, United Kingdom and Gland, Switzerland.

Devos, C., Sanz, C., Morgan, D., Onononga, J.-R., Laporte, N., Huynen, M.-C., 2008. Comparing ape densities and habitats in northern Congo: surveys of sympatric gorillas and chimpanzees in the Odzala and Ndoki regions. Am. J. Primatol. 70, 439-451.

East, R., 1999. African Antelope Database 1998. IUCN.

Evanno, G., Regnaut, S., Goudet, J., 2005. Detecting the number of clusters of individuals using the software STRUCTURE: a simulation study. Mol. Ecol. 14, 2611-2620.

Farr, T.G., Kobrick, M., 2000. Shuttle radar topography mission produces a wealth of data. EOS Trans. Am. Geophys. Union 81, 583.

Fay, J.M., 1991. An elephant (Loxodonta africana) survey using dung counts in the forests of the Central African Republic. J. Trop. Ecol. 7, 25-36.

Fleury-Brugiere, M.-C., Marie-Claire, F.-B., David, B., 2010. High population density of Pan troglodytes verus in the Haut Niger National Park, Republic of Guinea: implications for local and regional conservation. Int. J. Primatol. 31, 383-392.

Fünfstück, T., Arandjelovic, M., Morgan, D.B., Sanz, C., Reed, P., Olson, S.H., Cameron, K., Ondzie, A., Peeters, M., Vigilant, L., 2015. The sampling scheme matters: Pan troglodytes troglodytes and P. t. schweinfurthii are characterized by clinal genetic variation rather than a strong subspecies break. Am. J. Phys. Anthropol. 156, 181-191.

Ghiglieri, M.P., 1979. The Socio-ecology of Chimpanzees in Kibale Forest. Univ. of California, Davis, California.

Goodall, J., 1986. The Chimpanzees of Gombe: Patterns of Behavior. Belknap Press.

Goossens, B., Setchell, J.M., Tchidongo, E., Dilambaka, E., Vidal, C., Ancrenaz, M., Jamart, A., 2005. Survival, interactions with conspecifics and reproduction in 37 chimpanzees released into the wild. Biol. Conserv. 123, 461-475.

Hall, J.S., White, L.J.T., Inogwabini, B.-I., Omari, I., Morland, H.S., Williamson, E.A., Saltonstall, K., Walsh, P., Sikubwabo, C., Bonny, D., Kiswele, K.P., Vedder, A., Freeman, K., 1998. Survey of Grauer's Gorillas (Gorilla gorilla graueri) and Eastern Chimpanzees (Pan troglodytes schweinfurthi) in the Kahuzi-Biega National Park Lowland Sector and adjacent Forest in Eastern Democratic Republic of Congo. Int. J. Primatol. 19, 29.

Henriot, D., 2014. Au Bout des Pistes, le Chinko: Vie et Mort d'un Domaine de Chasse en Oubangui (1970-1997).

Hicks, T.C., Roessingh, P., Menken, S.B.J., 2012. Reactions of Bili-Uele chimpanzees to humans in relation to their distance from roads and villages. Am. J. Primatol. 74, 721-733.

Hicks, T.C., Sandra, T., Hjalmar, K., Geneviève, C., Jeroen, S., Laura, D., Christophe, B., John, H., Menken, S.B.J., 2014. Absence of evidence is not evidence of absence: discovery of a large, continuous population of Pan troglodytes schweinfurthii in the Central Uele region of northern DRC. Biol. Conserv. 171, 107-113.

Hillman, J.C., 1982. Wildlife Information Booklet: Democratic Republic of the Sudan.

IUCN SSC A.P.E.S. database, Drexel University, Jane Goodall Institute, 2016. Pan troglodytes. The IUCN Red List of Threatened Species Version 2016-3.
Ihobe, H., 2005. Life span of chimpanzee beds at the Mahale Mountains National Park, Tanzania. In: Pan Africa News. 12. pp. 10-12.

Junker, J., Jessica, J., Stephen, B., Christophe, B., Geneviève, C., du Toit, L., Chris, D., Atanga, E., Gilles, E., Anh, G.-L., Joel, G., Jessica, G.-S., Sylvain, G., Andrea, G., Nicolas, G., John, H., Josephine, H., Ilka, H., Hicks, T.C., Bas, H., Imong, I.S., Noëlle, K., Sally, L., Jeremy, L., Fiona, M., Matthew, M., Laura, M., Bethan, M., David, M., Felix, M., Roger, M., N'Goran, K.P., Emmanuelle, N., Anne, N., Okon, D.T., CharlesAlbert, P., Andrew, P., Hugo, R., Sébastien, R., Crickette, S., Emma, S., Adama, T., Sandra, T., Jacqueline, S.-G., Peter, W., Ymke, W., Williamson, E.A., Kuehl, H.S., 2012. Recent decline in suitable environmental conditions for African great apes. Divers. Distrib. 18, 1077-1091.

Kawanaka, K., Kenji, K., 1984. Association, ranging, and the social unit in chimpanzees of the Mahale Mountains, Tanzania. Int. J. Primatol. 5, 411-434.

Kormos, R., Boesch, C., Bakarr, M.I., Butynski, T., 2003. Status Survey and Conservation Action Plan: West African Chimpanzees. IUCN/SSC Primate Specialist Group. IUCN, Gland, Switzerland and Cambridge, UK.

Kouakou, C.Y., Boesch, C., Kuehl, H., 2009. Estimating chimpanzee population size with nest counts: validating methods in Taï National Park. Am. J. Primatol. 71, 447-457.

Kouakou, C.Y., Christophe, B., Kuehl, H.S., 2011. Identifying hotspots of chimpanzee group activity from transect surveys in Taï National Park, Côte d'Ivoire. J. Trop. Ecol. 27, 621-630.

Kühl, H., Maisels, F., Ancrenaz, M., Williamson, E.A., 2008. Best Practice Guidelines for Surveys and Monitoring of Great Ape Populations (No. 36). IUCN SSC primate Specialist Group (PSG), Gland, Switzerland.

Langergraber, K.E., Carolyn, R., Grit, S., Cathy, C., Catherine, H., Roman, W., Wrangham, R.W., Klaus, Z., Linda, V., 2014. How old are chimpanzee communities? Time to the most recent common ancestor of the Y-chromosome in highly patrilocal societies. J. Hum. Evol. 69, 1-7.

Mararv E. 2015, personal communication to Aebischer T.

Marchesi, P., Paul, M., Nathalie, M., Barbara, F., Christophe, B., 1995. Census and distribution of chimpanzees in Côte D'Ivoire. Primates 36, 591-607.

Matthews, A., Matthews, A., 2004. Survey of gorillas (Gorilla gorilla gorilla) and chimpanzees (Pan troglodytes troglodytes) in Southwestern Cameroon. Primates 45, 15-24.

McCarthy, M.S., Lester, J.D., Howe, E.J., Mimi, A., Stanford, C.B., Linda, V., 2015. Genetic censusing identifies an unexpectedly sizeable population of an endangered large mammal in a fragmented forest landscape. BMC Ecol. 15. http://dx.doi.org/10.1186/ s12898-015-0052-x.

Mitani, J.C., Watts, D.P., Pepper, J.W., Andrew M., D., 2002. Demographic and social constraints on male chimpanzee behaviour. Anim. Behav. 64, 727-737.

Moore, D.L., Vigilant, L., 2013. A population estimate of chimpanzees (Pan troglodytes schweinfurthii) in the Ugalla region using standard and spatially explicit genetic capture-recapture methods. Am. J. Primatol. 76, 335-346.

Morgan, D., Sanz, C., Onononga, J.R., Strindberg, S., 2006. Ape abundance and habitat use in the Goualougo Triangle, Republic of Congo. Int. J. Primatol. 27, 147-149.

Moyer, D., Plumptre, A.J., Kamenya, S., Athumani, S., Sikombe, S., 2006. Surveys east of Mahale Mountains National Park. In: Moyer, D., Plumptre, A.J., P., L., HernandezAguilar, A., Moore, J., Stewart, F.A., Davenport, T., Piel, A., Kamenya, S., Mugabe, H., Mpunga, N., Mwangoka, M. (Eds.), Surveys of Chimpanzees and Other Biodiversity in Western Tanzania. Wildlife Conservation Society. Jane Goodall Institute, University of California San Diego, pp. 20-23.

Ndallot, O.J., Lemaux J.A., Exalto, Y. (2015) personal communication to Aebischer T.

Newton-Fisher, N.E., 2003. The home range of the Sonso community of chimpanzees from the Budongo Forest, Uganda. Afr. J. Ecol. 41, 150-156.

Nishida, T., 1983. Alpha status and agonistic alliance in wild chimpanzees (Pan troglodytes schweinfurthii). Primates 24, 318-336.

Nishida, T., 1979. The social structure of chimpanzees of the Mahale Mountains. In: McKown, E.R. (Ed.), The Great Apes. Hamburg DR, Benjamin-Cummings, Menlo Park; Calif, pp. 73-121.

Nsubuga, A.M., Robbins, M.M., Roeder, A.D., Morin, P.A., Boesch, C., Vigilant, L., 2004. Factors affecting the amount of genomic DNA extracted from ape faeces and the identification of an improved sample storage method. Mol. Ecol. 13, 2089-2094.

Oates, J.F., 2006. Is the chimpanzee, Pan troglodytes, an endangered species? It depends on what "endangered" means. Primates 47, 102-112.

Oates, J.F., Tutin, C.E.G., Humle, T., Wilson, M.L., Baillie, J.E.M., Balmforth, Z., Blom, A., Boesch, C., Cox, D., Davenport, T., Dunn, A., Dupain, J., Duvall, C., Ellis, C.M., Farmer, K.H., Gatti, S., Greengrass, E., Hart, J., Herbinger, I., Hicks, C., Hunt, K.D., Kamenya, S., Maisels, F., Mitani, J.C., Moore, J., Morgan, B.J., Morgan, D.B., Nakamura, M., Nixon, S., Plumptre, A.J., Reynolds, V., Stokes, E.J., Walsh, P.D., 2008. Pan troglodytes [WWW Document]. The IUCN Red List of Threatened Species 2008. http://dx.doi.org/10.2305/IUCN.UK.2008.RLTS.T15933A5322627.en.

Ogawa, H., Hideshi, O., Gen'ich, I., Jim, M., Lilian, P., Adriana, H.-A., 2007. Sleeping parties and nest distribution of chimpanzees in the Savanna Woodland, Ugalla, Tanzania. Int. J. Primatol. 28, 1397-1412.

Ogawa, H., Hideshi, O., Jim, M., Shadrack, K., 2006. Chimpanzees in the Ntakata and Kakungu areas, Tanzania. Primate Conserv. 21, 97-101.

Plumptre, A.J., Reynolds, V., 1997a. Nesting behavior of chimpanzees: implications for censuses. Int. J. Primatol. 18, 475-485.

Plumptre, A.J., Reynolds, V., 1997b. Nesting behavior of chimpanzees: implications for censuses. Int. J. Primatol. 18, 475-485.

Plumptre, A.J., Reynolds, V., 1996. Censusing chimpanzees in the Budongo Forest, Uganda. Int. J. Primatol. 17, 85-99.

Plumptre, A.J., Rose, R., Nangendo, G., Williamson, E.A., Didier, K., Hart, J., Mulindahabi, F., Hicks, C., Griffin, B., Ogawa, H., Nixon, S., Pintea, L., Vosper, A., McClennan, M., Amsini, F., McNeilage, A., Makana, J.R., Kanamori, M., Hernandez, A., Piel, A., Stewart, F., Moore, J., Zamma, K., Nakamura, M., Kamenya, S., Idani, G., Sakamaki, T., Yoshikawa, M., Greer, D., Tranquilli, S., Beyers, R., Furuichi, T., 
Hashimoto, C., Bennett, E., 2010. Eastern Chimpanzee (Pan troglodytes schweinfurthii) Status Survey and Conservation Action Plan 2010-2020. IUCN, Gland, Switzerland.

Pritchard, J.K., Matthew, S., Rosenberg, N.A., Peter, D., 2000. Association mapping in structured populations. Am. J. Hum. Genet. 67, 170-181.

Pritchard, J., Wen, X., Falush, D., 2010. Documentation for Structure Software. Department of Human Genetics University of Chicago.

Pruetz, J.D., Fulton, S.J., Marchant, L.F., McGrew, W.C., Schiel, M., Waller, M., 2008. Arboreal nesting as anti-predator adaptation by savanna chimpanzees (Pan troglodytes verus) in southeastern Senegal. Am. J. Primatol. 70, 393-401.

Pruetz, J.D., Lindshield, S., 2012. Plant-food and tool transfer among savanna chimpanzees at Fongoli, Senegal. Primates 53, 133-145.

Pruetz, J.D., Marchant, L.F., Arno, J., McGrew, W.C., 2002. Survey of savanna chimpanzees (Pan troglodytes verus) in Southeastern Sénégal. Am. J. Primatol. 58, 35-43.

Puechmaille, S.J., 2016. The program structure does not reliably recover the correct population structure when sampling is uneven: subsampling and new estimators alleviate the problem. Mol. Ecol. Resour. 16, 608-627.

QGIS Development Team, 2014. QGIS Geographic Information System [WWW Document]. Open Source Geospatial Foundation Project. (URL http://www.qgis.org/ (accessed 16)).

Reed, D.H., O'Grady, J.J., Brook, B.W., Ballou, J.D., Richard, F., 2003. Estimates of minimum viable population sizes for vertebrates and factors influencing those estimates. Biol. Conserv. 113, 23-34.

Riggio, J., Jason, R., Andrew, J., Luke, D., Hans, B., Matthew, B., Amy, D., Paul, F., Rosemary, G., Philipp, H., de Iongh, H., Laly, L., Stuart, P., 2012. The size of savannah Africa: a lion's (Panthera leo) view. Biodivers. Conserv. 22, 17-35.

Roulet, P.A., Pelissier, C., Patek, G., Beina, D., Ndallot, J., 2007. Projet Zemongo - Un aperçu du contexte écologique et de la pression anthropique sur les resources naturelles de la Réserve de Faune de Zemongo, Préfecture du Haut-Mbomou, République Centrafricaine.

Schipper, J., Chanson, J.S., Chiozza, F., Cox, N.A., Hoffmann, M., Katariya, V., Lamoreux, J., Rodrigues, A.S.L., Stuart, S.N., Temple, H.J., Baillie, J., Boitani, L., Lacher, T.E., Mittermeier, R.A., Smith, A.T., Absolon, D., Aguiar, J.M., Amori, G., Bakkour, N., Baldi, R., Berridge, R.J., Bielby, J., Black, P.A., Blanc, J.J., Brooks, T.M., Burton, J.A., Butynski, T.M., Catullo, G., Chapman, R., Cokeliss, Z., Collen, B., Conroy, J., Cooke, J.G., da Fonseca, G.A.B., Derocher, A.E., Dublin, H.T., Duckworth, J.W., Emmons, L., Emslie, R.H., Festa-Bianchet, M., Foster, M., Foster, S., Garshelis, D.L., Gates, C., Gimenez-Dixon, M., Gonzalez, S., Gonzalez-Maya, J.F., Good, T.C., Hammerson, G., Hammond, P.S., Happold, D., Happold, M., Hare, J., Harris, R.B., Hawkins, C.E., Haywood, M., Heaney, L.R., Hedges, S., Helgen, K.M., Hilton-Taylor, C., Hussain, S.A., Ishii, N., Jefferson, T.A., Jenkins, R.K.B., Johnston, C.H., Keith, M., Kingdon, J., Knox, D.H., Kovacs, K.M., Langhammer, P., Leus, K., Lewison, R., Lichtenstein, G., Lowry, L.F., Macavoy, Z., Mace, G.M., Mallon, D.P., Masi, M., McKnight, M.W., Medellin, R.A., Medici, P., Mills, G., Moehlman, P.D., Molur, S., Mora, A., Nowell, K., Oates, J.F., Olech, W., Oliver, W.R.L., Oprea, M., Patterson, B.D., Perrin, W.F. Polidoro, B.A., Pollock, C., Powel, A., Protas, Y., Racey, P., Ragle, J., Ramani, P., Rathbun, G., Reeves, R.R., Reilly, S.B., Reynolds, J.E., Rondinini, C., Rosell-Ambal, R.G., Rulli, M., Rylands, A.B., Savini, S., Schank, C.J., Sechrest, W., Self-Sullivan, C., Shoemaker, A., Sillero-Zubiri, C., De Silva, N., Smith, D.E., Srinivasulu, C., Stephenson, P.J., van Strien, N., Talukdar, B.K., Taylor, B.L., Timmins, R., Tirira, D.G., Tognelli, M.F., Tsytsulina, K., Veiga, L.M., V, J.-C., Williamson, E.A., Wyatt, S.A., Xie, Y., Young, B.E., 2008. The status of the world's land and marine mammals: diversity, threat, and knowledge. Science 322, 225-230.

Serckx, A., Adeline, S., Marie-Claude, H., Jean-François, B., Alain, H., Beudels-Jamar, R.C., Marie, V., Emilien, R., Kühl, H.S., 2014. Nest grouping patterns of bonobos (Pan paniscus) in relation to fruit availability in a Forest-savannah mosaic. PLoS One 9, e93742.

Stewart, F.A., Piel, A.K., McGrew, W.C., 2011. Living archaeology: artefacts of specific nest site fidelity in wild chimpanzees. J. Hum. Evol. 61, 388-395.

Stuart, S.N., Chanson, J.S., Cox, N.A., Young, B.E., Rodrigues, A.S.L., Fischman, D.L., Waller, R.W., 2004. Status and trends of amphibian declines and extinctions worldwide. Science 306, 1783-1786.

Sugiyama, Y., Soumah, A.G., 1988. Preliminary survey of the distribution and population of chimpanzees in the Republic of Guinea. Primates 29, 569-574.

Sugiyama, Y., Yukimaru, S., Soumah, A.G., 1988. Preliminary survey of the distribution and population of chimpanzees in the Republic of Guinea. Primates 29, 569-574.

Tear, T.H., Scott, J.M., Hayward, P.H., Griffith, B., 1993. Status and prospects for success of the endangered species act: a look at recovery plans. Science 262, 976-977.

Teleki, G., Hunt, E.E., Pfifferling, J.H., 1976. Demographic observations (1963-1973) on the chimpanzees of Gombe National Park, Tanzania. J. Hum. Evol. 5, 559-598.

Thomas, L., Buckland, S.T., Rexstad, E., Laake, J.L., Strindberg, S., Hedley, S.L., Bishop, J.R.B., Marques, T.A.L.O., 2010. Distance Software: Design and Analysis of Distance Sampling Surveys for Estimating Population Size. http://dx.doi.org/10.1111/j.13652664.2009.01737.x.

Tidjani, I., 2015. Etude sur les incursions d'eleveurs transhumants dans l'aire de reserve du projet Chinko. Université de Bangui.

Traill, L.W., Bradshaw, C.J.A., Brook, B.W., 2007/9. Minimum viable population size: a meta-analysis of 30 years of published estimates. Biol. Conserv. 139, 159-166.

Tutin, C.E.G., Fernandez, M., 1984. Nationwide census of gorilla (gorilla g. gorilla) and chimpanzee (Pan t. troglodytes) populations in Gabon. Am. J. Primatol. 6, 313-336.

Tuttle, R., 1986. Apes of the World: Their Social Behavior, Communication, Mentality, and Ecology. Academic Press.

UNEP-WCMC, IUCN, 2016. Protected Planet Report 2016. Cambridge UK and Gland, Switzerland, UNEP-WCMC and IUCN.

Van Krunkelsven, E., 2001. Density estimation of bonobos (Pan paniscus) in Salonga National Park, Congo. Biol. Conserv. 99, 387-391.

Watts, D.P., 1998. Coalitionary mate guarding by male chimpanzees at Ngogo, Kibale National Park, Uganda. Behav. Ecol. Sociobiol. 44, 43-55.

Wikimedia, 16:45, 7, April 2011. File:Lesotho in Africa (special marker) (-mini maprivers).svg [WWW Document]. Wikimedia_Commons. (URL https://commons. wikimedia.org/wiki/File:Lesotho_in_Africa_(special_marker)_(-mini_map_-rivers).svg (accessed 16)).

Williamson, E., Bayogo, R., Guimiyessi, G., Ouangbao, P., Saboundou, A., Blake, S., Maisels, F., 2004. Survey of Elephants, Bangassou, Central African Republic: Conservation Status and Human Impacts. (May-June 2004).

Wilson, M.L., Wrangham, R.W., 2003. Intergroup relations in chimpanzees. Annu. Rev. Anthropol. 32, 363-392.

Wrangham, R.W., Chapman, C.A., Clark-Arcadi, A.P., Gilbert, I.-B., 1996. Social ecology of Kanyawara chimpanzees: implications for understanding the costs of great ape groups. In: McGrew, W.C., Marchant, L.F., Nishida, T. (Eds.), Great Ape Societies. Cambridge University Press, Cambridge; UK, pp. 45-57.

WWF, 2016. Living Planet Report 2016. Risk and Resilience in a new era. WWF, Gland, Switzerland. 